\title{
THE EFFECT OF DIFFERENT TOURNAMENT STAGES ON THE MOVEMENT DYNAMICS OF FUTSAL PLAYERS WHILE IN BALL POSSESSION
}

original paper

( ) University School of Physical Education in Wroclaw

DOI: https://doi.org/10.5114/hm.2021.103292

\author{
SHARIMAN ISMADI ISMAIL ${ }^{1,2}$, HIROYUKI NUNOME ${ }^{3}$ \\ ${ }^{1}$ Universiti Teknologi MARA, Shah Alam, Malaysia \\ ${ }^{2}$ Graduate School of Sports and Health Science, Fukuoka University, Fukuoka, Japan \\ ${ }^{3}$ Fukuoka University, Fukuoka, Japan
}

\begin{abstract}
Purpose. This study aimed to classify typical futsal movement patterns while in ball possession and clarify the effect of tournament stages on these movement profiles.

Methods. A total of 5647 movements in possession of a ball during 8 international futsal matches were analysed. These matches consisted of 4 group stages, and there were 4 knockout stage matches ( 2 semi-finals, a third-place play-off, and the final). On the basis of the observation of 2 experienced analysts, 8 translational and rotational movement indicators were established: forward translation, backward translation, sideway translation, and slow rotation (defined as the low traction demand movement), and side-cut, $\mathrm{u}$-cut, fast rotation, and sudden stop (defined as the high traction demand movement).

Results. The overall results highlighted that $82.48 \%$ of the analysed movements were translational movements [top-three highest movements proportion: (1) forward translation: 26.52\%, (2) side-cut: $15.76 \%$, and (3) sideway translation: $14.36 \%$ ]. Furthermore, there was a significantly higher frequency of translational movements among players during knockout stage matches ( $p=0.03$ ), suggesting that these translational movements form the foundation aspects in maintaining ball possession. Also, a significantly higher occurrence was observed for 2 high traction demand movements [u-cut $(p=0.02)$ and fast rotation $(p<0.0001)]$ during knockout stage matches compared with group stage matches.
\end{abstract}

Conclusions. High traction demand translational movements related to changes of direction were significantly influenced by the stages of the tournament in highly competitive futsal matches.

Key words: indoor soccer, movement classification, possession-play, tournament stages

\section{Introduction}

Futsal is a fast-paced, small sided football game characterized by the speed of movement, high intensity, and great spatial awareness of the players [1, 2]. In futsal, players have less time and space to play when compared with association football (soccer). In the context of these differences, there were interests from the scientific perspective on the activity profile of futsal players [3-5]. In addition, research has focused on how futsal-specific motions are different or similar in comparison with soccer-specific motions [6, 7]. Most of these studies, however, investigated only the general locomotor activities such as walking, running, and sprinting.

A study by Reilly and Thomas [8] was the first one to illustrate discrete activities (other than locomotion) performed by professional soccer players depending on different playing positions. This study was a catalyst for other researchers to adopt a similar analytic model in order to establish sport-specific movement and characteristics classification $[9,10]$. Better understanding of sport-specific athlete movement also helped to produce specific skills and performance measurement system [11, 12]. All of these studies, in some way, are the continuation of the earlier works by Franks and Goodman [13] and Bartlett [14], who tried to combine biomechanical applications and notational analysis to improve the athletes' performance, thereby setting a new trend in sports performance analysis.

In previous studies, the majority of researchers used the 'normative' profiling approach when identifying a movement classification $[9,10,15,16]$. From this

Correspondence address: Shariman Ismadi Ismail, Faculty of Sports Science and Recreation, Universiti Teknologi MARA, 40450 Shah Alam, Selangor Darul Ehsan, Malaysia, e-mail: shariman_ismadi@uitm.edu.my

Received: March 4, 2020

Accepted for publication: May 16, 2020

Citation: Ismail SI, Nunome H. The effect of different tournament stages on the movement dynamics of futsal players while in ball possession. Hum Mov. 2021;22(4):68-77; doi: https://doi.org/10.5114/hm.2021.103292. 
classification procedure, only specific players' movements whose occurrence frequency differed by less than $5 \%$ between all analysed matches were selected. However, this procedure is likely to neglect some important aspects of players' movements whose occurrence frequency is variable between matches. For instance, ball possession is a factor significantly contributing to the match outcomes in football codes [17, 18], which would have a substantial impact on the movement profile of players on either end. Likewise, the stages of tournaments would alter the players' dynamics during competitive matches. However, there has been no study to take into account the effect of these key performance indicators on the players' movement profiles. It has been reported that futsal players' match organization, physical and technical performance were different in matches with different levels of opponents and of different tournament stages [19]. Similar findings were also reported in soccer [20]. These observations might suggest that there is a need to verify the effect of key performance indicators on players' movement dynamics.

Thus, the aims of this study were (1) to classify typical movement patterns while in ball possession during actual futsal matches and (2) to clarify the influence of different tournament stages on futsal players' movement profiles. It was expected that players' movement intensity would increase during matches in the later stage of the tournament. We therefore hypothesized that different tournament stages would alter the movement dynamics of futsal players while in ball possession.

\section{Material and methods}

\section{Samples}

A total of 8 futsal matches from the 2014 ASEAN Futsal Championship (AFF Futsal Championship) were recorded and observed. The sample was formed by 4 group stage games (Thailand vs. Philippines, Australia vs. Brunei, Indonesia vs. Brunei, and Vietnam vs. Philippines), 2 semi-finals (Thailand vs. Indonesia - semi-final 1, and Australia vs. Vietnam - semi-Final 2), a third-place play-off (Indonesia vs. Vietnam), and the final (Thailand vs. Australia). The final also represented 2 best futsal teams in Asia in accordance with the Futsal World Ranking (Thailand: world rank No. 17, Australia: world rank No. 21 when the tournament started). In conjunction to the aim of this study, these matches were chosen to obtain contrasting match data, representing best performing teams vs. best performing teams and best performing teams vs. worst performing teams (the bottom team during group stages such as Brunei and Philippines).

\section{Instruments}

The players' movements were initially observed and selected during the earlier stage (group stage matches) of the competition. From previous studies that extracted futsal-specific movements, 14 different types of primary movement performed by futsal players were identified [10]. Of these movements, 8 primary movements (forward translation, backward translation, sideway translation, and slow rotation; side-cut, u-cut, fast rotation, and sudden stop) were chosen and re-classified in this study, in which the movement of run was expanded into 2 categories (forward translation and backward translation), 6 movements remotely related to ball possession (sprint, fall, get up, jump, land, impact) were excluded, and movements associated with the players stopping with an immediate manner (shuffle and stop) were integrated as 'sudden stop'.

Also, in this study, an attempt was made to estimate the nature of interaction between players and the playing surface (traction demand) because shoeplaying surface traction/friction is an essential factor when players need to achieve a chosen manoeuvre [21], thereby affecting sports performance [22] and injury risk prevention [23]. Each movement was categorized depending on the movement speed and per-

Table 1. Definitions of movement classification

\begin{tabular}{llc}
\hline Movement categories & \multicolumn{1}{c}{ Definition of movement } & Traction demand \\
\hline 1. Forward translation & Moving the body forward & Low \\
2. Backward translation & Moving the body backward & Low \\
3. Sideway translation & Moving the body laterally & Low \\
4. Slow rotation & Turning the body slowly & Low \\
5. Fast rotation & Turning the body quickly & High \\
6. U-cut (translation) & Changing running movement in the opposite $\left(180^{\circ}\right)$ direction & High \\
7. Side-cut (translation) & Changing running movement direction through an acute angle & High \\
8. Sudden stop (translation) & Sudden brake from a very fast movement & High \\
\hline
\end{tabular}


S. Ismail, H. Nunome, Futsal ball-possession movement

ceived impression of its intensity into low traction demand or high traction demand. The descriptions of the movement categories are shown in Table 1.

\section{Procedures}

One Full HD video camera (set at $1920 \times 1080$ pixels, 50 frames per second) was utilized to record all futsal matches in the competition. The video camera was positioned so as to obtain the side view of the futsal pitch from the highest position behind the audience area. In this study, players' movements while in ball possession were analysed. The inclusion criteria of the types of movement to be analysed were as follows:

(i) Movements made by players who were in ball possession, excluding the goalkeeper.

(ii) Any kind of movements causing body rotation or translation by using the support leg while another leg was controlling the ball.

\section{Data analysis}

All recorded matches were analysed with the Kinovea (v. 0.8.15) and Dartfish EasyTag (v. 1.0.8) software (Figure 1). Kinovea, a valid and reliable tool for human movement analysis [24], served to perform the notational analysis of the ball and players' movement by using the slow-motion movement features (up to $90 \%$ speed reduction compared with the original video speed).

During the movement tracking process, each video frame that included the movement required for clas- sification was tagged by using the built-in Kinovea features. This was followed by tagging the related movement in Dartfish EasyTag [25, 26], installed on a separate device (a tablet computer). All analysis was executed after the matches completed (post-game analysis). Two experienced performance analysts carried out the notational analysis of all the 8 matches. Before the notational analysis began, an investigator informed the 2 analysts about how to classify and identify the movement indicators.

Both analysts performed all the match analyses independently. Each analyst conducted the notational analysis twice for each match, with 48 hours separating the first and the second analysis. Intra- and interanalyst reliability studies were applied to examine the reliability of the analysed data. The reliability was calculated on the basis of the percentage of intra- and inter-analyst differences by using the approach suggested by Hughes and Franks [27]. The calculation of the percentage difference for the intra- and inter-analyst reliability is shown in equation (1) and (2), respectively:

$$
\begin{gathered}
\delta_{\text {INTRA }}=\left(\frac{V_{1}-V_{2}}{V_{M}}\right) \times 100 \\
\delta_{\text {INTER }}=\left(\frac{V_{M}-V_{m}}{V_{M}}\right) \times 100
\end{gathered}
$$

where $V_{1}$ and $V_{2}$ are the individual data for each analyst for the $1^{\text {st }}$ and the $2^{\text {nd }}$ analysis, $V_{m}$ is the mean difference of data from each analyst, and $V_{M}$ is the common mean of both analysts.

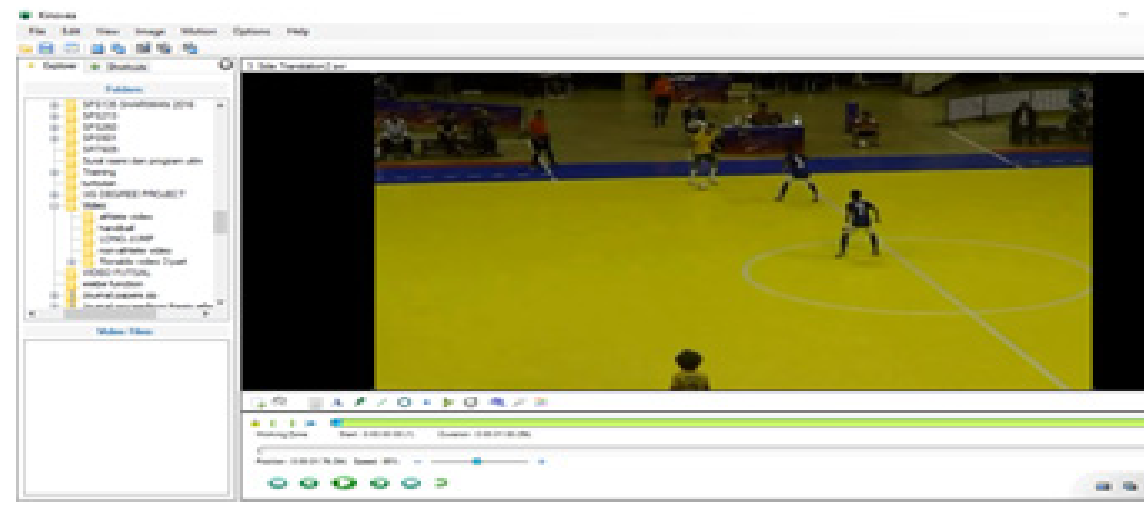

Figure 1. The Kinovea (left) and EasyTag (right) software

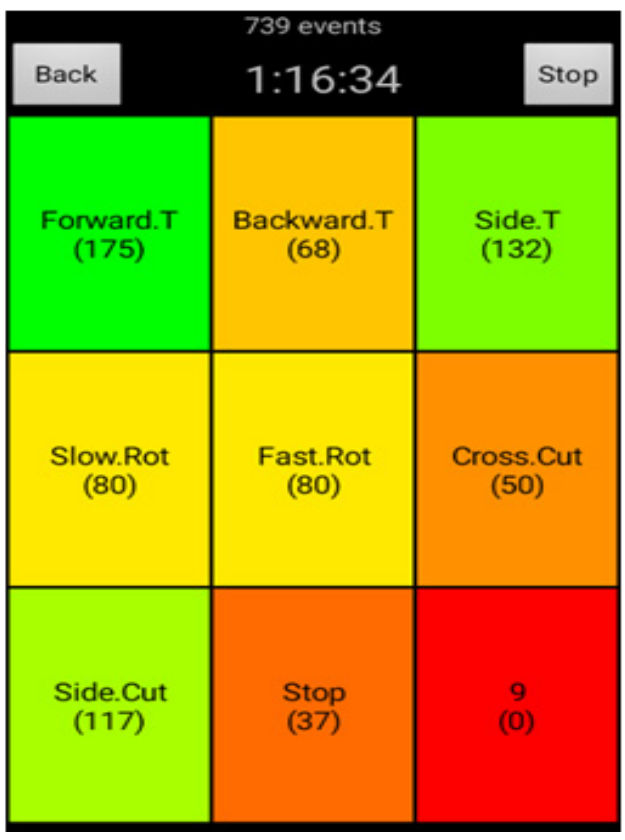


Table 2. Intra- and inter-analyst reliability analysis

\begin{tabular}{|c|c|c|c|c|c|}
\hline \multicolumn{4}{|c|}{ Intra-analyst } & \multicolumn{2}{|c|}{ Inter-analyst } \\
\hline \multicolumn{2}{|c|}{ Mean $(\%)(S D)$} & \multicolumn{2}{|c|}{ Correlation coefficient } & \multirow{2}{*}{ Mean $(\%)(S D)$} & \multirow{2}{*}{$\begin{array}{l}\text { Correlation } \\
\text { coefficient }\end{array}$} \\
\hline A1 & A2 & A1 & A2 & & \\
\hline $4.89(0.65)$ & $4.67(0.51)$ & $\begin{array}{c}0.993 \text { (95\% CI: } \\
0.988-0.995)\end{array}$ & $\begin{array}{c}0.994 \text { (95\% CI: } \\
0.990-0.996)\end{array}$ & $3.4(0.62)$ & $\begin{array}{l}0.99 \text { (95\% CI: } \\
0.985-0.994)\end{array}$ \\
\hline
\end{tabular}

A1 - analyst No. 1, A2 - analyst No. 2

In addition, the intra- and inter-analyst reliability was also determined by using the correlation coefficient [28], analysed with the WinPepi (v. 11.65) statistical package [29]. The results of the intra- and inter-analyst reliability are shown in Table 2 . As the percentage of differences was below $5 \%$ and all the calculated correlation coefficients were above 0.99 , it can be judged that the analyses performed by the 2 analysts are reliable and thus the mean values from both analysts were used for further analysis.

Mean values and variation percentage from the mean values for all movement indicators were calculated. The differences between the group stage and the knockout stage data were compared by using an independent sample $t$-test at the confidence level of 0.05 .

\section{Ethical approval}

The conducted research is not related to either human or animal use.

\section{Results}

The results consist of 3 main parts. The first part illustrates the findings concerning the overall trend of movement classification (Figures 2 and 3). The second part shows the mean match-to-match variation in the occurrence of all movements (Table 3). The third part presents the outcomes for the comparison between group stage and knockout stage matches (Figures 4-6).

\section{Movement classification breakdown: overall trend}

Overall, a total of 5647 movements performed by futsal players in 8 matches during the 2014 AFF Futsal Championship were classified into 8 categories (Figure 2).

As shown in Figure 2, forward translation (26.52\%) was found to be the most frequently performed movement by the futsal players while in ball possession, followed by side-cut (15.76\%), sideway translation (14.36\%), u-cut $(12.25 \%)$, fast rotation $(8.97 \%)$, backward translation (8.55\%) and slow rotation (8.55\%).

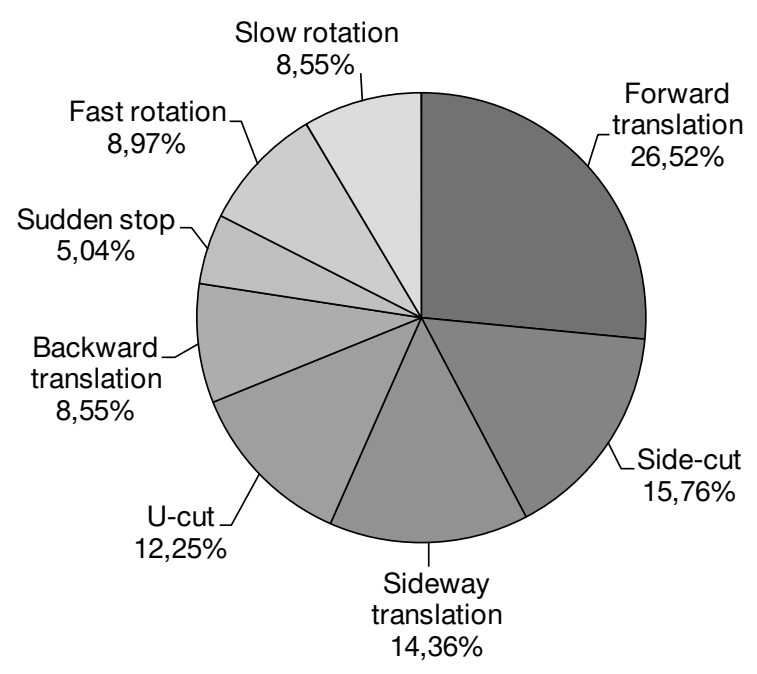

Figure 2. The occurrence of particular movement categories $(n=5647)$

(a)

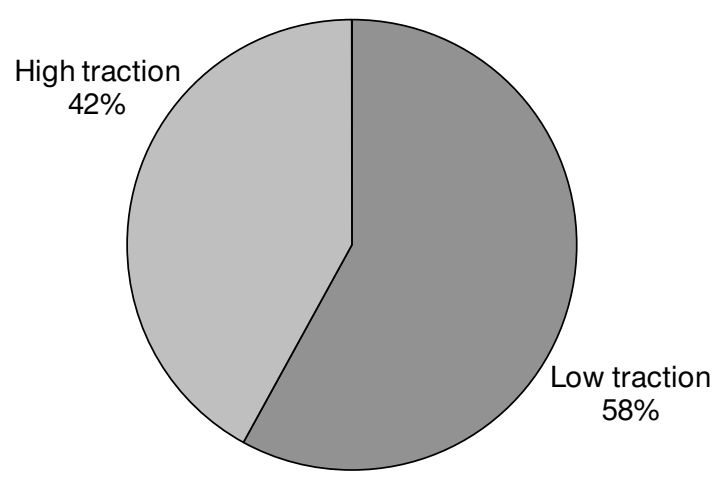

(b)

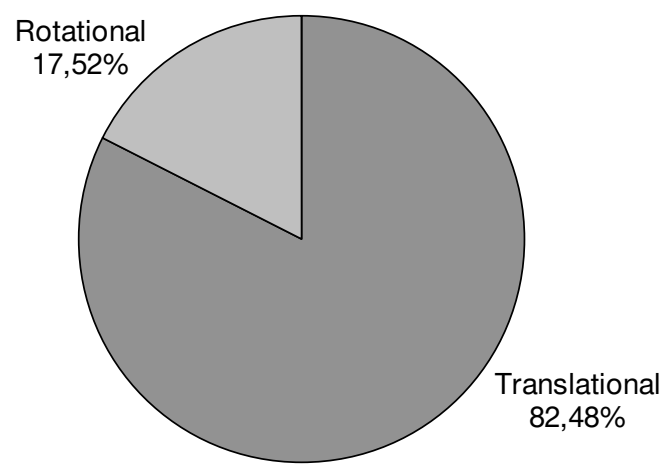

Figure 3. The occurrence of particular movement categories by (a) perceived traction demand and (b) translational and rotational movement $(n=5647)$ 


\section{HUMAN MOVEMENT}

S. Ismail, H. Nunome, Futsal ball-possession movement

The least frequently performed movement was the sudden stop (5.04\%).

Figures $3 \mathrm{a}$ and $3 \mathrm{~b}$ show the relative frequencies of movements by high and low perceived traction demand (Figure 3a) and translational and rotational nature (Figure 3b). It was found that the players performed more low traction demand movements (58.00\%) than high traction demand movements (42.00\%); also, more translational movements $(82.48 \%)$ were applied by the players when compared with rotational movements (17.52\%).

Variations (from the mean value) among matches

Table 3 summarizes the variations of occurrence of all movements between the matches. As shown, there were no movements that varied by less than $5 \%$ between the 8 analysed matches. Only 3 classification items were found to vary by less than $10 \%$ throughout all the analysed matches (backward translation: 7.81\%, forward translation: $8.33 \%$, and side-cut: $9.94 \%$ ), while 4 classification items varied by more than $20 \%$ : u-cut (20.05\%), fast rotation (20.38\%), sideway translation (23.86\%), and slow rotation (31.79\%).

\section{Comparison between group stage}

and knockout stage matches

Figure 4 shows the comparison of the total occurrence of all movement categories between the group stage and the knockout stage. It can be seen that the total number of classified movements significantly increased during the knockout stage matches compared with those of the group stage (group stage: 2630 vs. knockout stage: $3017, p=0.04$ ). Side-cut and slow rotation movements were found to be reduced during the knockout stage matches (side-cut: from 459 to 431; slow rotation: from 248 to 235).

Figure 5 compares the relative occurrence of low and high traction demand movements (Figure 5a) and

Table 3. The mean match-to-match variation (\%) of the occurrence of movements in all analysed matches

\begin{tabular}{|c|c|c|c|c|c|c|c|c|}
\hline $\begin{array}{l}\text { Movement } \\
\text { categories }\end{array}$ & $\begin{array}{l}\text { Backward } \\
\text { translation }\end{array}$ & $\begin{array}{c}\text { Forward } \\
\text { translation }\end{array}$ & Side-cut & $\begin{array}{l}\text { Sudden } \\
\text { stop }\end{array}$ & U-cut & $\begin{array}{c}\text { Fast } \\
\text { rotation }\end{array}$ & $\begin{array}{c}\text { Sideway } \\
\text { translation }\end{array}$ & $\begin{array}{l}\text { Slow } \\
\text { rotation }\end{array}$ \\
\hline $\begin{array}{l}\text { Mean of } \\
\text { variation (\%) } \\
(S D)\end{array}$ & $\begin{array}{c}7.81 \\
(0.06)\end{array}$ & $\begin{array}{c}8.33 \\
(0.06)\end{array}$ & $\begin{array}{c}9.94 \\
(0.12)\end{array}$ & $\begin{array}{l}12.97 \\
(0.11)\end{array}$ & $\begin{array}{l}20.05 \\
(0.09)\end{array}$ & $\begin{array}{l}20.38 \\
(0.11)\end{array}$ & $\begin{array}{l}23.86 \\
(0.12)\end{array}$ & $\begin{array}{l}31.79 \\
(0.15)\end{array}$ \\
\hline
\end{tabular}

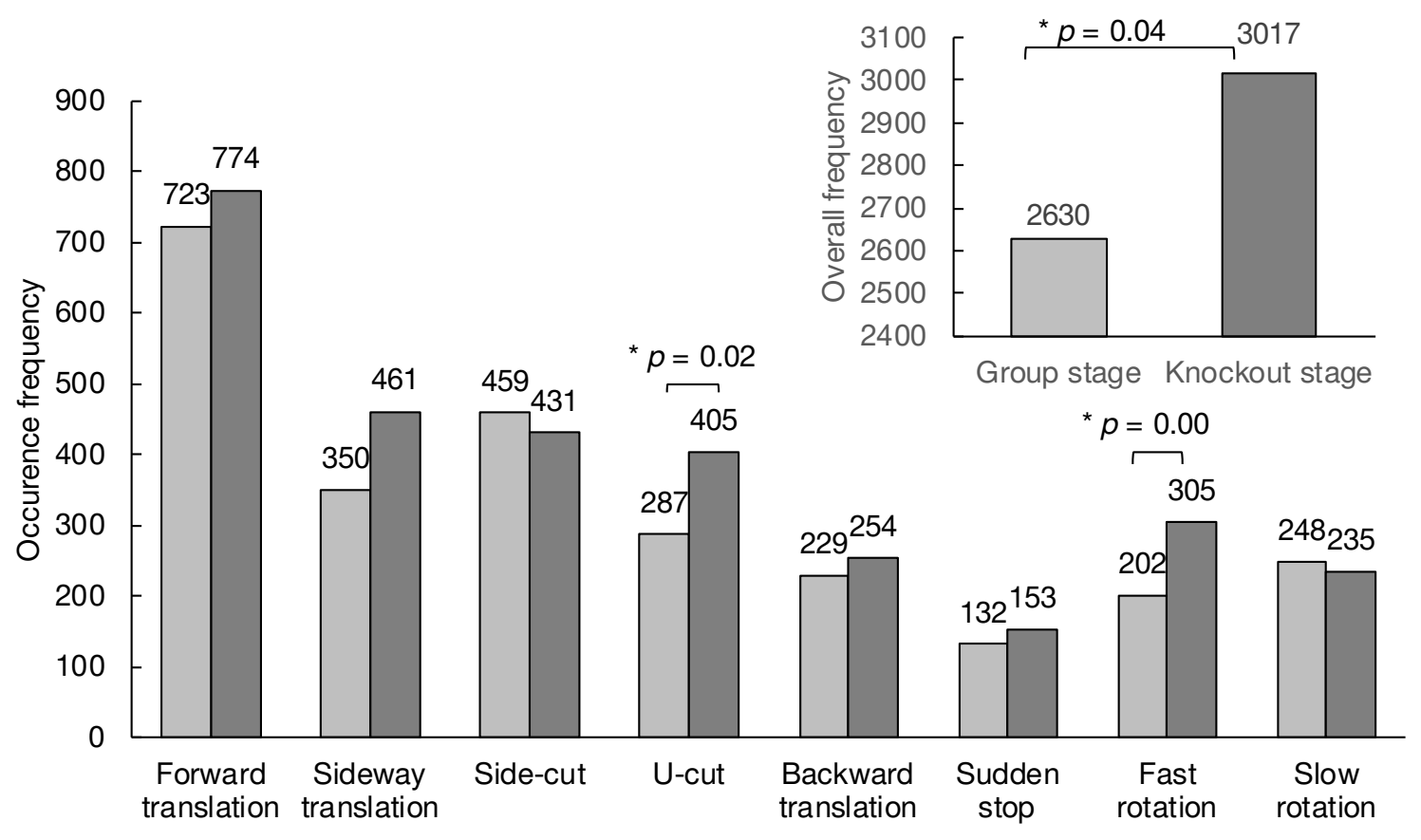

$\square$ Group stage $\quad \square$ Knockout stage

${ }^{*} p<0.05:$ independent sample $t$-test results

Figure 4. Occurrence of all movement categories during group and knockout stage matches 
(a)

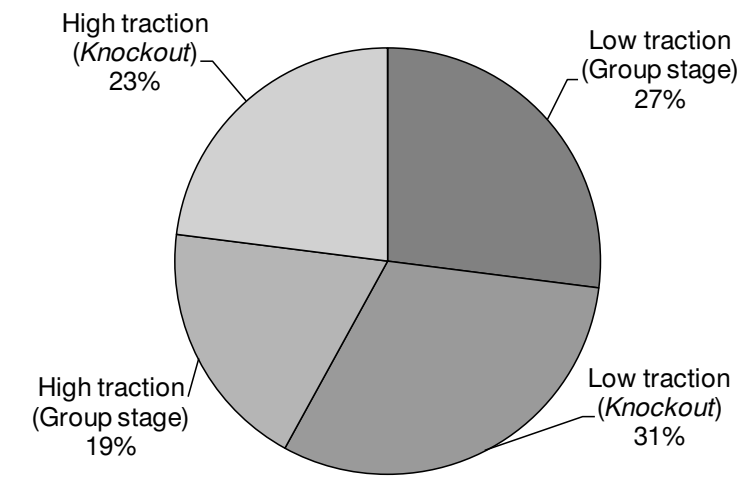

(b)

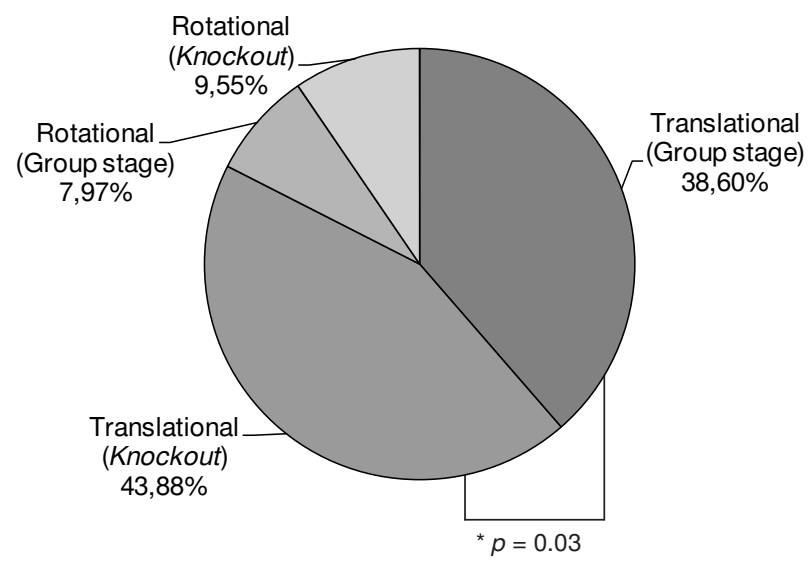

${ }^{*} p<0.05$ : independent sample $t$-test results

Figure 5. Relative occurrence of all movement categories in the group and knockout stage matches by (a) perceived traction demand and (b) translational and rotational movements

(a)

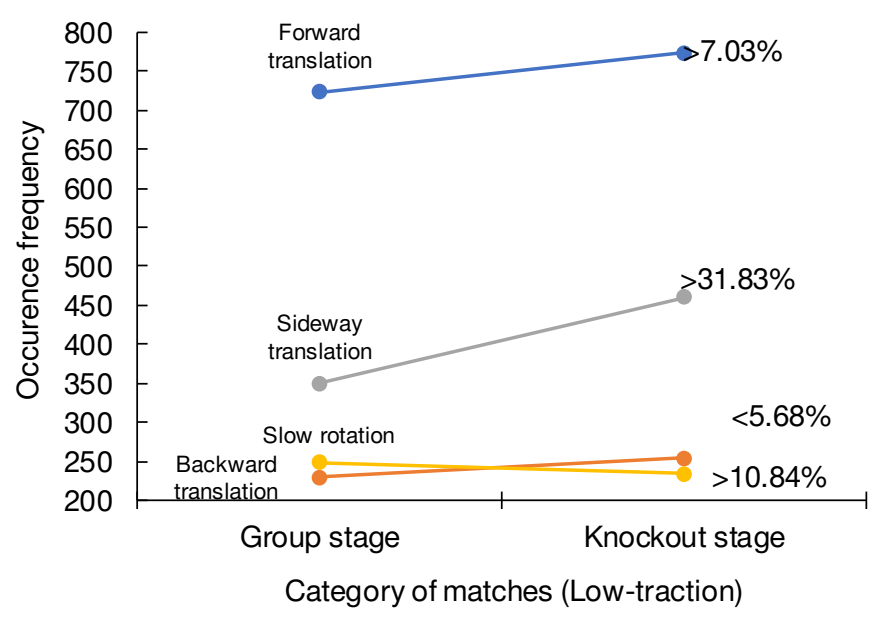

(b)

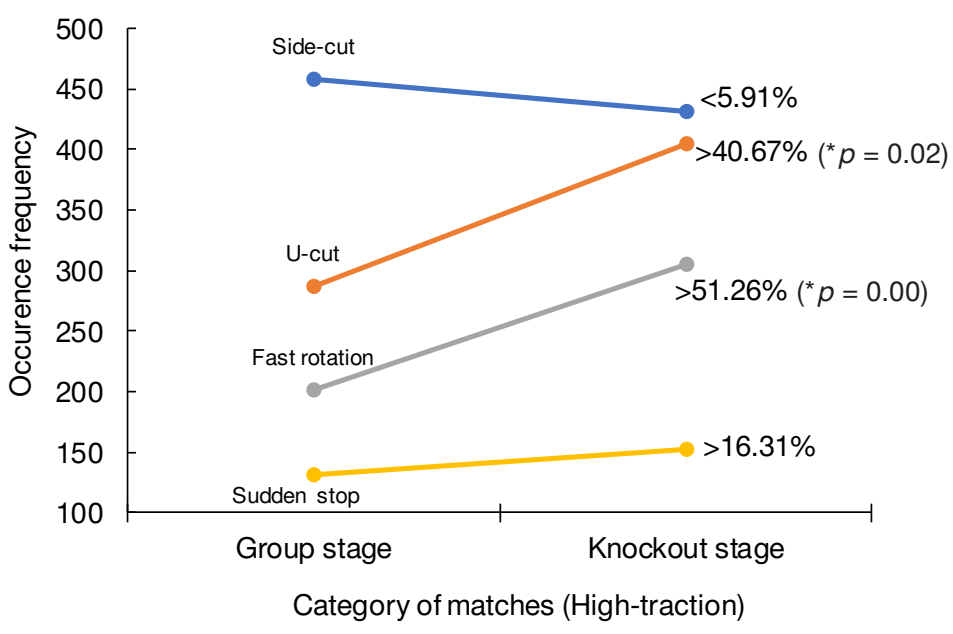

${ }^{*} p<0.05$ : independent sample $t$-test results

Figure. 6. Changes of relative occurrence for low (a) and high (b) traction demand movements at different stages

translational and rotational nature movements (Figure $5 \mathrm{~b}$ ) between the 2 stage matches. An increase of the total frequency of low and high traction demand movements was noticed for the knockout stage matches compared with those of the group stage, though these changes were not significant (Figure 5a). It can also be observed that both translational and rotational related movements increased during the knockout stage matches, as shown in Figure 5b, where a significant increase was found for translational movement ( $p=$ $0.03)$. No significant change was established for rotational movement.

Figure 6 shows the change of occurrence of low and high traction demand movement classification items between the group and knockout stages. Among the low traction demand items (Figure 6a), sideway translation recorded the highest percentage of increase toward the knockout stage (31.83\%) followed by backward translation (10.84\%) and forward translation $(7.03 \%)$, while slow rotation was the only item that exhibited a reduction trend (5.68\%). However, there was no significant difference for these items between the 2 stages. On the other hand, a significant increase was found for $\mathrm{u}$-cut $(+40.67 \%, p=0.02)$ and fast rotation $(+51.26 \%, p=0.00)$ among high traction demand items between the 2 stages, while no significant differences were observed for the other high traction demand items (Figure 6b). Of these items, side-cut was the only item that showed reduction (5.91\%) toward the knockout stage. 


\section{Discussion}

The first aim of this study was to illustrate typical movement patterns in actual futsal matches. A previous attempt in characterizing futsal movements extracted 14 different types of primary movements among futsal players [10]. However, the study included several redundant movement categories, such as player stopping, player breaking heavily from a sprint, and player in collision phase. Therefore, in this study, all movements associated with the players' stopping with an immediate manner were integrated and classified as 'sudden stop'. Also, the movement categories considered not to have strong association with ball-possession aspects, such as jumping and landing, were eliminated from the analysis. Moreover, movements were further divided into low and high traction demand categories from the perspective of shoe-playing surface interaction aspects.

To date, studies regarding movement profiling commonly assume that a 'normative profile' should be achieved to establish a certain movement classification, typically using the standard criteria allowing $5 \%$ variation between matches $[10,15]$. However, in this study, we found that none of the movements met the "normative' standard provided in the literature. On the contrary, there were only 3 movements (forward translation, backward translation, side-cut) that exhibited some consistency of occurrence frequencies in all matches (less than $10 \%$ variation). These findings demonstrate a highly variable nature of futsal movements. Most of previous studies tend to profile players' movements by following only one individual player or team through multiple matches $[9,10]$. Therefore, it is logical to assume that a homogeneous player group would perform less-varied movements through all matches, thereby showing less variated patterns. This type of approach, commonly used in previous studies, might not represent the true nature of players' movements because the number and diversity of players were considerably limited. Similarly, previous studies that observed higher numbers of athletes typically have a limited time window for analysis [30]. This was a critical limitation of these studies and a possible explanation why they reported less variable movement profiles. In this study, a large number of different players (at least 24) were involved in an analysis of 8 competitive matches (full-time) in 2 different stages during an international level futsal competition. This may explain why none of the analysed movements met the commonly applied normative profile standard (less than $5 \%$ variation) established in the literature. In this circumstance, it was suggested here that the variation criterion of $5 \%$ should be reconsidered in light of the presented findings. In this study, only 3 movement categories (forward translation, backward translation, and side-cut) can be judged to have some consistency (less than $10 \%$ variation). Hughes et al. [15] proposed that the normative movement profile could be defined differently depending on the study population and variables. On this basis, it can be proposed that the 10\% criterion would be more reasonable as the standard for normative classification in this study.

Contrarily, the movement categories which did not meet the normative criteria, such as u-cut and fast rotation, should not be discarded. In this study, we found that the relative occurrence of fast rotation and $\mathrm{u}$-cut increased significantly during the knockout stage matches, indicating the importance of these movements in more competitive situations. The significance of these movements should therefore be emphasized, even if they do not meet the normative standard. It must be mentioned here that movements similar to fast rotation or $\mathrm{u}$-cut have been widely adopted as experimental tasks for laboratory-based biomechanical testing [31] but there has been no strong justification of the reason for this choice. This finding likely provides a reasonable rationale on why these movements are tested in laboratory-based settings.

Overall, the most frequently executed movement was translational movement, with $82.48 \%$ of total occurrence. This result supports the previous findings and confirms the importance of translational or linear movements of athletes in futsal [10], as well as in other sports such as soccer, handball, volleyball, and basketball [32-34]. We also revealed that of the many translational movements, the majority was low traction demand (58\%), in which forward and sideway translation were most utilized (occurrence of $26.52 \%$ and $14.36 \%$, respectively.

Moreover, among high traction demand movements, side-cut was found to be the most frequently utilized, accounting for $15.76 \%$ of total occurrence. In addition, the significant increase of overall translational movements during knockout stage matches (Figure 5b) highlights the important role of translational movement aspects in futsal. It is also clear that while rotational movements are regarded as important in human movement studies [35], their execution among futsal players was relatively low in this study. A series of findings related to translational movements in this study indicates the significance of these movements in forming the foundation aspects for futsal players in maintaining ball possession. 
The second aim of this study was to investigate the effect of different tournament stages on the futsal movement classification. Through comparisons between matches from the group stage (strong vs. weak teams) and the knockout stage (strong vs. strong teams), it was established that during the knockout stage matches, the futsal players increased their movement intensity. This could be verified by the significant increases of overall movement (Figure 4) and translational movement (Figure 5b) occurrence during the knockout stage matches.

Moreover, from the perceived traction demand aspects, it was found that there were only 2 high traction demand movements (u-cut and fast rotation) that were significantly different $(p<0.05)$ in terms of the mean frequency when compared between the group and the knockout stage matches (Figure 6b). This study is the first to demonstrate significant changes in movement patterns while in ball possession in futsal matches from different tournament stages, suggesting that the players are adapted to change their playing direction more frequently using high traction demand movements during higher competitive environment. This is because during the knockout stage, the quality of opponents was arguably higher and they tended to defend better [36]. This could have potentially contributed to creating more difficult situations for players on attacking, such as dribble past the facing defender. Thus, the consequences of these scenarios were likely represented as a significant increase of $\mathrm{u}$-cut and fast rotation occurrence during the knockout stage matches.

To further elaborate, these increments (u-cut and fast rotation) demonstrate that as players in the attacking mode tend to face some difficulty in penetrating the opponents' goal area, more deeper cut and fast rotation movements are performed during the knockout stage in order to maintain ball possession and to relaunch the attacking movement. The unique changes seen in this study could have been reflected by tactical behaviours among successful sports teams that were capable to alter their movements when facing constraints from the opponent defensive formation [37].

Finally, in this study, the ball possession, the tournament stages, and the perceived traction demand aspects were considered as the key factors that could influence movements performed by the players. In terms of the practical approach, the current findings highlight the importance of external factors such as the tournament stage, which may partially reflect the opponent's competitive level. The same principle can be applied in other football codes, too.

\section{Conclusions}

A list of movement categories while in ball possession executed by futsal players has been presented. The results indicate that while not all of these movement categories achieved the commonly applied normative profile definitions, translation movements such as forward translation, backward translation, and sidecut run were consistently executed by players. It was also found that $\mathrm{u}$-cut and fast rotation movements were significantly influenced by the tournament stages. Moreover, it was noticed that the movement rates of occurrence, particularly those of translational movements, significantly increased in futsal matches among the best performing teams during the knockout stage matches. There were also more changes of direction related movements observed in higher stage competitive matches. As a result, these movements (side-cut and u-cut: $28.01 \%$ of occurrence rate, collectively) were found to be substantial in representing futsal players' motion.

\section{Acknowledgments}

The authors would like to thank Norasrudin Sulaiman, Kamarul Siddiq Mohd Sulaiman, and Muhamad Farith Nasrin Nasaruddin from Universiti Teknologi MARA, Malaysia, for their assistance with data collection and analysis during the investigation.

\section{Disclosure statement}

No author has any financial interest or received any financial benefit from this research.

\section{Conflict of interest}

The authors state no conflict of interest.

\section{References}

1. Moore R, Radford J. Is futsal kicking off in England? A baseline participation study of futsal. Am J Sports Sci Med. 2014;2(3):117-122; doi: 10.12691/ajssm-2-3-9.

2. Wolański P, Muracki J, Goliński D, Nosal J, BakońskaPacoń E, Murawska-Ciałowicz E. The intensity and energy expenditure of exertions, restitution speed, and rate of perceived exertion after tournament matches in Polish futsal players. Hum Mov. 2017;18(1):58-66; doi: 10.1515/humo-2017-0008.

3. Barbero-Alvarez JC, Soto VM, Barbero-Alvarez V, Granda-Vera J. Match analysis and heart rate of futsal players during competition. J Sports Sci. 2008;26(1):6373; doi: 10.1080/02640410701287289.

4. Castagna C, D’Ottavio S, Vera JG, Barbero Álvarez JC. Match demands of professional futsal: a case study. J Sci Med Sport. 2009;12(4):490-494; doi: 10.1016/j. jsams.2008.02.001. 
S. Ismail, H. Nunome, Futsal ball-possession movement

5. Doğramaci S, Watsford ML, Murphy AJ. Activity profile differences between sub-elite futsal teams. Int J Exerc Sci. 2015;8(2):112-123.

6. Jiménez-Reyes P, García-Ramos A, Cuadrado-Peñafiel V, Párraga-Montilla JA, Morcillo-Losa JA, Samozino $\mathrm{P}$, et al. Differences in sprint mechanical force-velocity profile between trained soccer and futsal players. Int J Sports Physiol Perform. 2019;14(4):478-485; doi: 10.1123/ijspp.2018-0402.

7. Milanović Z, Sporiš G, Trajković N, Fiorentini F. Differences in agility performance between futsal and soccer players. Sport Sci. 2011;4(2):55-59.

8. Reilly T, Thomas V. A motion analysis of work-rate in different positional roles in professional football matchplay. J Hum Mov Stud. 1976;2:87-97.

9. Bloomfield J, Polman R, O’Donoghue P. The 'Bloomfield Movement Classification': motion analysis of individual players in dynamic movement sports. Int J Perform Anal Sport. 2004;4(2):20-31; doi: 10.1080/24748 668.2004.11868300.

10. Emery J, Driscoll HF, Barnes A, James DM. A method for characterizing high acceleration movements in smallsided football. Procedia Eng. 2016;147:718-723; doi: 10.1016/j.proeng.2016.06.256.

11. Nicholas CW, Nuttall FE, Williams C. The Loughborough Intermittent Shuttle Test: a field test that simulates the activity pattern of soccer. J Sports Sci. 2000; 18(2):97-104; doi: 10.1080/026404100365162.

12. Russell M, Benton D, Kingsley M. Reliability and construct validity of soccer skills tests that measure passing, shooting, and dribbling. J Sports Sci. 2010;28(13): 1399-1408; doi: 10.1080/02640414.2010.511247.

13. Franks IM, Goodman D. A systematic approach to analysing sports performance. J Sports Sci. 1986;4(1):4959; doi: 10.1080/02640418608732098.

14. Bartlett R. Performance analysis: can bringing together biomechanics and notational analysis benefit coaches? Int J Perform Anal Sport. 2001;1(1):122-126; doi: 10.1080/24748668.2001.11868254.

15. Hughes M, Evans S, Wells J. Establishing normative profiles in performance analysis. Int J Perform Anal Sport. 2001;1(1):1-26; doi: 10.1080/24748668.2001. 11868245.

16. O’Donoghue P. Normative profiles of sports performance. Int J Perform Anal Sport. 2005;5(1):104-119; doi: 10.1080/24748668.2005.11868319.

17. Castellano J, Casamichana D, Lago C. The use of match statistics that discriminate between successful and unsuccessful soccer teams. J Hum Kinet. 2012;31:137147; doi: 10.2478/v10078-012-0015-7.

18. Ismail SI, Nunome H. The key performance indicators that discriminate winning and losing, and successful and unsuccessful teams during 2016 FIFA Futsal World Cup. Sci Med Football. 2020;4(1):68-75; doi: 10.1080/24733938.2019.1662937.

19. Palucci Vieira LH, Doğramaci SN, Barbieri RA, Milioni F, Moura FA, de Andrade VL, et al. Preliminary re- sults on organization on the court, physical and technical performance of Brazilian professional futsal players: comparison between friendly pre-season and official match. Motriz: Rev Educ Fis. 2016;22(2):79-91; doi: 10.1590/S1980-6574201600020011.

20. Folgado H, Duarte R, Fernandes O, Sampaio J. Competing with lower level opponents decreases intra-team movement synchronization and time-motion demands during pre-season soccer matches. PLoS One. 2014; 9(5):e97145; doi: 10.1371/journal.pone.0097145.

21. Barry B, Milburn P. Tribology, friction and traction: understanding shoe-surface interaction. Footwear Sci. 2013;5(3):137-145; doi: 10.1080/19424280.2013.797030.

22. Sterzing T, Müller C, Hennig EM, Milani TL. Actual and perceived running performance in soccer shoes: a series of eight studies. Footwear Sci. 2009;1(1):5-17; doi: 10.1080/19424280902915350.

23. Dixon S, Fleming P, James I, Carré M (eds.). The science and engineering of sport surfaces. Abingdon: Routledge; 2015.

24. Puig-Diví A, Escalona-Marfil C, Padullés-Riu JM, Busquets A, Padullés-Chando X, Marcos-Ruiz D. Validity and reliability of the Kinovea program in obtaining angles and distances using coordinates in 4 perspectives. PLoS One. 2019;14(6):e0216448; doi: 10.1371/ journal.pone.0216448.

25. Pill S, Elliott S. Effects of altering the number of players and the dimensions of the playing area on the possession characteristics in youth Australian football. Sport Sci Rev. 2015;24(3-4):171-192; doi: 10.1515/ssr2015-0014.

26. Cross Z, Pill S, Williams K. Comparing possession characteristics between 12,15 , and 18 a side games in junior Australian footballers. Sportlogia. 2018;14(1): 1-11; doi: 10.5550/sgia.181401.en.cpw.

27. Hughes MF, Franks IM. Notational analysis of sport. London: E \& FN Spon; 1997.

28. O’Donoghue P, Ingram B. A notational analysis of elite tennis strategy. J Sports Sci. 2001;19(2):107-115; doi: 10.1080/026404101300036299.

29. Abramson JH. WINPEPI updated: computer programs for epidemiologists, and their teaching potential. Epidemiol Perspect Innov. 2011;8(1):1; doi: 10.1186/17425573-8-1.

30. Bloomfield J, Polman R, O’Donoghue P. Physical demands of different positions in FA Premier League soccer. J Sports Sci Med. 2007;6(1):63-70.

31. De Clercq D, Debuyck G, Gerlo J, Rambour S, Segers V, Van Caekenberghe I. Cutting performance wearing different studded soccer shoes on dry and wet artificial turf. Footwear Sci. 2014;6(2):81-87; doi: 10.1080/194 24280.2014.895056.

32. Gréhaigne J-F, Godbout P, Bouthier D. Performance assessment in team sports. J Teach Phys Educ. 1997; 16(4):500-516; doi: 10.1123/jtpe.16.4.500.

33. McGhie D, Ettema G. Biomechanical analysis of traction at the shoe-surface interface on third-generation 
artificial turf. Sports Eng. 2013;16(2):71-80; doi: 10.1007/s12283-013-0115-1.

34. Wannop JW. Influence of basketball shoe mass, traction and bending stiffness on athletic performance. Footwear Sci. 2013;5(Suppl. 1):S98-S100; doi: 10.1080/ 19424280.2013.799580.

35. Wannop JW, Stefanyshyn DJ. The effect of translational and rotational traction on lower extremity joint loading. J Sports Sci. 2016;34(7):613-620; doi: 10.1080/ 02640414.2015.1066023.

36. Flores V, Rech R. Implications of goals and generally incurred by age in time team finalists and other participants in the category sub-15 competitions organized by Caxiense Futsal League in the year 2008 and 2009 [in Portuguese]. Rev Bras Futsal Futebol. 2012;4(11): $17-22$.

37. Travassos B, Bourbousson J, Esteves PT, Marcelino R, Pacheco M, Davids K. Adaptive behaviours of attacking futsal teams to opposition defensive formations. Hum Mov Sci. 2016;47:98-105; doi: 10.1016/j.humov.2016. 02.004 . 